\title{
Avaliação da contaminação no entorno de um aterro de resíduos sólidos urbanos com base em resultados de poços de monitoramento
}

\author{
Assessment of the contamination on the surrounding of a \\ municipal solid waste landfill based on monitoring wells data
}

Giulliana Mondelli', Heraldo Luiz Giacheti², Jorge Hamada²

口-

\section{RESUMO}

Este artigo apresenta o monitoramento ambiental das águas subterrâneas do entorno do aterro de resíduos sólidos urbanos (RSU) de Bauru, São Paulo, Brasil. Paralelamente às diversas pesquisas realizadas na área durante o período de janeiro de 2003 a abril de 2008, foram construídos 14 poços de monitoramento em diferentes fases da investigação geoambiental, seguindo as normas vigentes na época e as necessidades observadas durante a interpretação dos resultados desta investigação, para confirmação da contaminação da área. As amostras foram coletadas com bailer, após o período dechuvas e deestiagem decadaano. São apresentados os resultados obtidos ao longo do tempo para os seguintes parâmetros: nível d’água, $\mathrm{pH}$, condutividade elétrica (CE), $\mathrm{Ca}^{2+}, \mathrm{Cl}$, Fe total, $\mathrm{DQO}, \mathrm{NH}_{4}^{+}, \mathrm{Zn}^{2+}, \mathrm{Na}^{+}, \mathrm{K}^{+}$, além da relação demanda biológica de oxigênio/demanda química de oxigênio (DBO/DQO). Os resultados do longo período de monitoramento permitiram a análise de cada parâmetro em função do que ocorria superficialmente ao aterro, assim como com características naturais do aquífero. Conclui-se que a pluma de contaminação varia conforme o ponto de disposição e as características dos resíduos depositados, cuja recuperação e atenuação deverão ocorrer com o encerramento das atividades do aterro.

Palavras-chave: investigação geoambiental; aterro de resíduos sólidos urbanos; águas subterrâneas; pluma de contaminação.

\begin{abstract}
This paper presents the environmental monitoring of the groundwater surrounding the municipal solid waste disposal site from Bauru, São Paulo, Brazil. In parallel with the several surveys carried out at this site, between January 2003 and April 2008, fourteen monitoring wells were installed at different periods of the geoenvironmental site investigation, following the Brazilian standards valid at that time and the demands observed with the interpretation of the site investigation data, to confirm the local contamination. The samples were collected using bailer, after rains and drought periods each year. The results obtained over time are presented, for the following parameters: groundwater table, $\mathrm{pH}$, electrical conductivity, $\mathrm{Ca}^{2+}, \mathrm{Cl}$; total Fe, DQO, $\mathrm{NH}_{4}^{+}, \mathrm{Zn}^{2+}, \mathrm{Na}^{+}, \mathrm{K}^{+}$, and the ratio BOD/COD. The results of the long period of monitoring allowed the analysis of each parameter compared with what was happening superficially on the landfill, as well as natural characteristics of the aquifer. It is concluded that the contamination plume varies according to the layout and characteristics of the disposed waste, which recovery and mitigation should occur with the closure of the landfill.
\end{abstract}

Keywords: geoenvironmental site investigation; municipal solid waste landfill; groundwater; contamination plume.

\section{INTRODUÇÃO}

Os locais de disposição de resíduos sólidos urbanos (RSU) têm recebido especial atenção nos últimos anos, por representarem potencial fonte de contaminação do solo, da água e do ar. Diversos são os locais em que os resíduos não estão dispostos adequadamente, abrangendo extensas áreas, não observando as limitações legais e desobedecendo a normas e técnicas de manejo adequado.
Muitos países desenvolvidos já contam com tradição na questão do monitoramento da qualidade de solos e águas subterrâneas e no controle de áreas contaminadas. Seguindo o exemplo, a Companhia Ambiental do Estado de São Paulo (CETESB) publicou, em 2005, uma lista preliminar de valores orientadores, atualizada em 2014, para proteção da qualidade dos solos e das águas subterrâneas, os quais foram estabelecidos para agilizar e facilitar as decisões para prevenção e controle da poluição dos solos e das

'Engenheira Civil; Professora Adjunta do Centro de Engenharia, Modelagem e Ciências Sociais Aplicadas da Universidade Federal do ABC (UFABC) - Santo André (SP), Brasil. ¿Engenheiro Civil; Professor Titular do Programa de Pós-Graduação em Engenharia Civil e Ambiental da Universidade Estadual "Júlio de Mesquita Filho" (UNESP) - Bauru (SP), Brasil. Endereço para correspondência: Giulliana Mondelli - Universidade Federal do ABC (UFABC-CECS) - Avenida dos Estados, 5001 - Bangu - 09210-580 - Santo André (SP), Brasil E-mail: g.mondelli@ufabc.edu.br

Recebido: 15/07/13 - Aceito: 08/06/15 - Reg. ABES: 120706 
águas subterrâneas. Sánchez (2001) lembra que, apesar da facilidade, o uso de padrões de qualidade pode originar situações muito rígidas ou mesmo insuficientes para proteção do meio em questão. Deve ser lembrado que certos usos e formas de ocupação não exigem uma qualidade ótima do solo.

Os valores de intervenção para as águas subterrâneas adotados pela CETESB $(2005 ; 2014)$ podem ser muito rigorosos quando aplicados às águas do entorno de um local de disposição de resíduos, uma vez que foram estabelecidos a partir dos padrões de potabilidade do Ministério da Saúde. A exemplo da Resolução CONAMA nº 357/2005, alterada pelas Resoluções no 410/2009 e nº 430/2011, que definem limites para diferentes usos das águas superficiais, a Resolução CONAMA n 396/2008 estabelece limites para diferentes usos das águas subterrâneas brasileiras. Além do consumo humano, sugere valores para dessedentação de animais, irrigação e recreação. Apesar dos recentes avanços nota-se, ainda, a inexistência de limites para alguns parâmetros importantes na avaliação da poluição e da contaminação das águas subterrâneas, tais como demanda biológica de oxigênio (DBO), demanda química de oxigênio (DQO), alcalinidade, condutividade elétrica (CE), etc.

Para que a existência da contaminação seja confirmada, é necessária a realização de uma completa investigação de campo e laboratório, para caracterização e quantificação da contaminação e/ou poluição possivelmente existentes. Essa investigação geoambiental, como é conhecida, é fundamental para indicação de um reúso adequado do terreno, implicando em alternativas de remediação viáveis.

A utilização de ensaios de geofísica de superfície, ensaios de piezocone de resistividade (RCPTU), com sonda Membrane Interface Probe (MIP), em conjunto com a construção e o monitoramento de poços para coleta de águas subterrâneas e amostragem prévia de solos, tem proporcionado uma melhor caracterização geoambiental do subsolo e essas técnicas de investigação têm sido incorporadas pela Environmental Protection Agency of United States (USEPA) desde 2003 (ITRC, 2003). Alguns autores (DAVIES \& CAMPANELLA, 1995; BOLINELLI JUNIOR et al., 2005; DE MIO et al., 2005; MONDELLI et al., 2010; GANDOLFO; MONDELLI; BLANCO, 2012; DIAS et al., 2013) têm mostrado a aplicação de métodos indiretos como etapa de investigação e monitoramento de locais de disposição de resíduos. A prática de escavação direta para caracterização do terreno, como a sondagem de simples reconhecimento (SPT) e as amostragens de água de poços de monitoramento e piezômetros, é considerada tradicional e corrente em obras geotécnicas no Brasil, mas nem sempre no caso de investigação de áreas contaminadas ou potencialmente contaminadas.

Talvez por serem mais conhecidos, os poços de monitoramento são tidos como parte indispensável da investigação e do monitoramento de áreas contaminadas ou potencialmente contaminadas, constituindo a principal exigência dos órgãos ambientais em todo o mundo (MACEDO et al., 2011; ADEREMI et al., 2011). Hoje, no Brasil, a construção desses poços, assim como a coleta de água subterrânea dos mesmos, deve seguir a norma da ABNT NBR 15495-1, de 2007, atualização da antiga norma ABNT NBR 13895, de 1997, a qual estava em vigência quando da execução dos poços apresentados no presente trabalho.

O objetivo deste trabalho foi apresentar e discutir os resultados da análise química das águas subterrâneas coletadas de poços de monitoramento instalados no entorno de um aterro de RSU no interior do Estado de São Paulo, no período de janeiro de 2003 a abril de 2008. Os resultados desse monitoramento, que abrangeu um período de seis anos, foram acompanhados de outros ensaios realizados na mesma área, que auxiliaram na interpretação dos mesmos.

\section{CARACTERIZAÇÃO DA ÁREA DE ESTUDO}

$\mathrm{O}$ aterro de RSU estudado situa-se no município de Bauru, interior do Estado de São Paulo (Figura 1) e ocupava uma área de aproximadamente $270.000 \mathrm{~m}^{2}$ até 2008, quando as pesquisas na área foram encerradas. O aterro então recebia cerca de 220.000 t.dia $^{-1}$ de resíduos sólidos domiciliares (Classe II-A) e também resíduos de serviços de saúde em valas sépticas, distribuídas na face sul-sudeste do aterro. $\mathrm{O}$ fundo $\mathrm{e}$ as laterais das valas sépticas recebiam uma camada de CM-30 (asfalto diluído), antes da deposição dos resíduos.

De acordo com a Fundação para o Incremento da Pesquisa e do Aperfeiçoamento Industrial (FIPAI, 1992), a proteção da base do aterro deveria ser feita com 4 camadas de $20 \mathrm{~cm}$ de solo, compactadas $3 \%$ acima do teor de umidade ótimo, com rolo pé-de-carneiro. Sobre essa camada foi executada uma imprimação betuminosa com asfalto diluído CM-30, em duas demãos. Essa forma de execução foi aprovada na época de implantação do aterro, que opera desde 1993. Foram feitas escavações até que o solo de alteração (horizonte C ou regolito) fosse alcançado. Demonstrou-se que o nível d'água, na época de implantação, estava a cerca de $2 \mathrm{~m}$ da base do aterro, segundo os resultados das sondagens SPT realizadas naquela época.

O aterro está localizado em zona rural (Figura 1), sendo as principais atividades existentes em seu entorno: pecuária, plantações de cana-de-açúcar e a presença de uma penitenciária. Acredita-se que as atividades pecuárias existentes em praticamente todo o entorno do aterro devem estar influenciando a qualidade das águas dos poços de monitoramento, o que justifica o presente trabalho.

Pelo fato de o aterro ocupar uma área extensa, a quantidade de chorume coletada pelo sistema de drenagem pode ser considerada muito pequena, denotando falhas na impermeabilização e, possivelmente, no sistema de drenagem subsuperficial. Além disso, por não contar com um sistema de tratamento e destinação final de chorume até 2007, o volume coletado era recirculado para lagoas de chorume existentes sobre o aterro, sendo que boa parte se infiltrava novamente na massa de resíduos. Uma vez que não havia descarte, presume-se que a maior parte do chorume infiltrava no subsolo.

Outro problema frequentemente encontrado no aterro, na época de realização das pesquisas, era a quebra dos equipamentos de operação, responsáveis pela compactação e cobertura dos resíduos. Sem a 
disponibilidade de equipamentos sobressalentes, durante os períodos de manutenção (por vezes longos), os resíduos ficavam expostos, aumentando a infiltração de água e também o escoamento superficial de chorume, comprometendo tanto os mananciais subterrâneos como os superficiais.

O aterro está situado sobre uma área caracterizada geologicamente por rochas do Grupo Bauru (Formação Marília nas cotas mais elevadas e Formação Vale do Rio do Peixe, antiga "Formação
Adamantina", nas cotas mais baixas), de idade Mesozoica, que ocupa todo o Planalto Ocidental do Estado de São Paulo. É importante salientar que o Aquífero Bauru, que corresponde à superfície saturada das formações citadas anteriormente, ocupa aproximadamente a metade do território paulista (47\%), além do sul de Minas Gerais e norte do Paraná, possuindo uma área aproximada de afloramento de $117.000 \mathrm{~km}^{2}$.

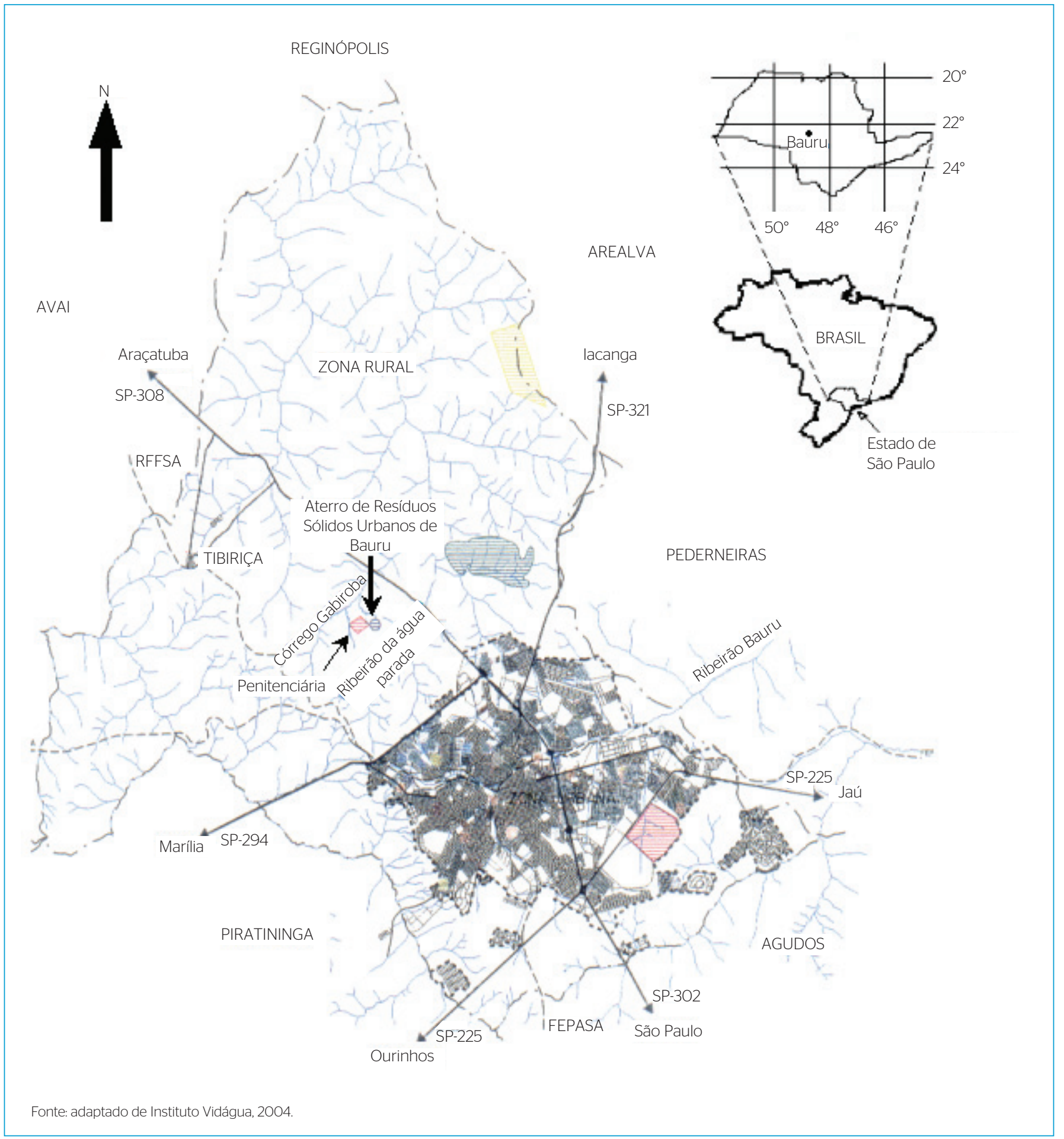

Figura 1 - Localização de Bauru no Estado de São Paulo e do aterro de resíduos sólidos urbanos na área rural do município. 
Na região onde está localizado o aterro, os sedimentos do Grupo Bauru, assim como seu solo de alteração, residual, estão sobrepostos por camadas de aluvião e colúvio. A Figura 1 mostra que o aterro fica entre vales constituídos de dois córregos. As cotas de superfície do relevo variam entre 551 e $523 \mathrm{~m}$. Com base nos poços de monitoramento localizados ao redor do aterro, o nível freático varia entre 521 e $519 \mathrm{~m}$ nas cotas mais elevadas e entre 515 e $517 \mathrm{~m}$ nas cotas mais baixas.

A interpretação dos resultados das sondagens SPT realizadas antes da implantação do aterro mostra que, à medida que se caminha para oeste, a camada de solo coluvionar dá espaço ao solo aluvionar (jusante). O colúvio cobria praticamente toda a região onde se encontra o aterro e os resultados das sondagens SPT indicam que o solo que ocorre na área tem as mesmas características do solo residual do Grupo Bauru, classificado como areia argilosa vermelha, laterítica. O solo da área do aterro possui textura de areia fina a média argilosa, com valores de coeficiente de permeabilidade variando entre $10^{-7}$ e $10^{-6} \mathrm{~m} \cdot \mathrm{s}^{-1}$ e entre $10^{-8} \mathrm{e}$ $10^{-9} \mathrm{~m} \cdot \mathrm{s}^{-1}$, quando compactado. Na área onde estão dispostos os resíduos, as cotas em que aparece o solo de alteração de arenito variam entre 522 e 543,4 m, enquanto o arenito, ou o impenetrável das sondagens SPT, aparece entre as cotas 518,5 (zona de vale) e 540,7 m (montante).

A Figura 2 apresenta o posicionamento dos poços de monitoramento construídos no entorno do aterro, sobre o levantamento topográfico realizado em 2007. O fluxo subterrâneo foi obtido conforme a interpolação dos níveis d'água estimados a partir de sondagens elétricas verticais (SEVs). Com base no mapa de fluxo subterrâneo estimado (Figura 3), o gradiente hidráulico é da ordem de 0,05 , no sentido leste-oeste.

Todos os ensaios de campo realizados na área durante as pesquisas mostraram que existe uma pluma de contaminação em um sentido principal, a oeste, e no sentido do fluxo subterrâneo local (Figura 4), que está sendo identificada desde o início das pesquisas, em 2001. Os resultados indicam que essa não é a única pluma formada, devido à ineficiência da camada de proteção da base do aterro, havendo outras que dependem da época, do tipo e da frente de disposição dos resíduos (MONDELLI, 2008). Essas plumas obtidas por meio da geofísica de superfície orientaram o posicionamento dos poços, assim como a necessidade da continuidade do monitoramento do aquífero ao longo dos anos de operação do aterro, apresentados no presente trabalho.

\section{METODOLOGIA}

Foram realizadas doze campanhas de amostragem de água, entre janeiro de 2003 e abril de 2008, que contribuíram para a interpretação dos resultados de ensaios geoambientais realizados e discutidos por Mondelli (2008). Esses estudos prévios contaram com resultados de ensaios geofísicos e de piezocone de resistividade e SPTs.

A Figura 5 apresenta o perfil típico e as características dos poços de monitoramento permanentes construídos ao redor do aterro pela empresa responsável. Esses poços de monitoramento foram instalados em duas etapas, quais sejam: setembro de 2002 (PP-1 a PP-9) e fevereiro de 2006 (PP-3A e PP-10 a PP-13). Estes últimos foram construídos com o objetivo de monitorar uma possível contaminação da água subterrânea advinda das valas sépticas preenchidas com resíduos hospitalares, a sul-sudeste do aterro. Em agosto de 2006, mais dois poços foram construídos (PP-5A e PP-5B), com o objetivo de confirmar ou não a elevada contaminação constatada no poço PP-5 até julho de 2006.

Inicialmente, em 2002, foram construídos dois poços considerados de montante: PP-4, a leste (Figura 2), e PP-6, ao sul do aterro (que está fora dos limites da Figura 2). Durante as diversas campanhas de coleta das águas desses poços, observou-se que o poço PP-4 apresentava valores elevados de CE, pH, DBO, DQO, E.coli e metais em relação aos outros poços considerados como de jusante. O poço PP-6 apresentava baixos valores de $\mathrm{pH}$, condutividade, cloretos, entre outros parâmetros. Contudo, devido à grande estiagem ocorrida em julho de 2006, o nível de água do poço PP-6 baixou consideravelmente, dificultando as amostragens. Nesse poço foram detectados valores elevados de fosfato, DQO, coliformes, $\mathrm{Zn}^{2+}$, Fe total, $\mathrm{Na}^{+}, \mathrm{K}^{+}$e $\mathrm{Ca}^{2+}$, em relação às campanhas anteriores. Outra observação relevante é que o poço PP-6 não está localizado em uma área com as mesmas características hidrogeológicas dos demais, por estar situado em compartimento hidrogeológico distinto. Dessa forma, os poços PP-10 e PP-13 foram construídos em 2006 com o objetivo de se obter referenciais confiáveis (background) para os demais e que não apresentassem contaminação.

O poço PP-3 foi substituído pelo poço PP-3A a partir de 2006, quando apresentou raízes na água. Desse modo, foram realizadas análises químicas para o PP-3 até 08 de novembro de 2005 e para o PP-3A a partir de 4 de julho de 2006.

As campanhas de amostragem eram executadas, em média, a cada seis meses, sendo sempre uma coleta realizada no período chuvoso e outra no período de estiagem. O método de coleta utilizado foi aquele da norma ABNT NBR 13895/1997, que era válida na época, e depois substituída pela norma ABNT NBR 15495-1/2007. Vinte e quatro horas antes da coleta era feito o esgotamento dos poços, por meio de bomba de sucção ou bailer, a depender da altura da coluna d'água e da taxa de recuperação de cada poço. As coletas eram então feitas no dia seguinte, a partir de bailer e frascos previamente preparados para recebimento das amostras. Temperatura, pH e CE eram medidos in situ e então as amostras eram imediatamente levadas para o laboratório em caixas térmicas com gelo, para análise dos demais parâmetros químicos, como cloretos, carbono orgânico total (COT), sulfatos, sulfetos, nitrogênio amoniacal $\left(\mathrm{NH}_{4}^{+}\right)$, nitratos, nitritos, nitrogênio total, fosfato, demanda bioquímica de oxigênio $\left(\mathrm{DBO}_{5}\right)$, demanda química de oxigênio (DQO), coliformes totais, E. coli, zinco, chumbo, níquel, cádmio, ferro, cromo, com base nos métodos publicados pela American Public Health Association (APHA, 1995), adotados pelo Laboratório de Saneamento da Escola de Engenharia de 
São Carlos da Universidade de São Paulo (EESC-USP). Os parâmetros $\mathrm{Na}^{+}, \mathrm{K}^{+}$e Ca ${ }^{2+}$ passaram a ser analisados a partir de 2005. De abril de 2004 a março de 2005, as coletas de água foram realizadas por Lopes (2007).

Os resultados das análises foram interpretados considerando sempre o menor valor dos padrões de qualidade para consumo de água humano estabelecidos pelo Conselho Nacional do Meio Ambiente (CONAMA), com a Resolução no 357 (para águas doces superficiais de Classe II), pela Portaria n 518, de 26 de março de 2004, do Ministério da Saúde
(BRASIL, 2004), e pela CETESB (2005), que eram válidas na época. Contudo, foram adotados valores de referência para o presente estudo com base nas características hidrogeológicas locais, de acordo com os valores máximos observados para poços de exploração do Aquífero Bauru e publicados pela CETESB (2004). Nesse caso, foram considerados os resultados dos seguintes poços da Companhia de Saneamento Básico do Estado de São Paulo (SABESP): Avaí P1, Presidente Alves P1 e Gália P2 (Formações Marília e Adamantina).

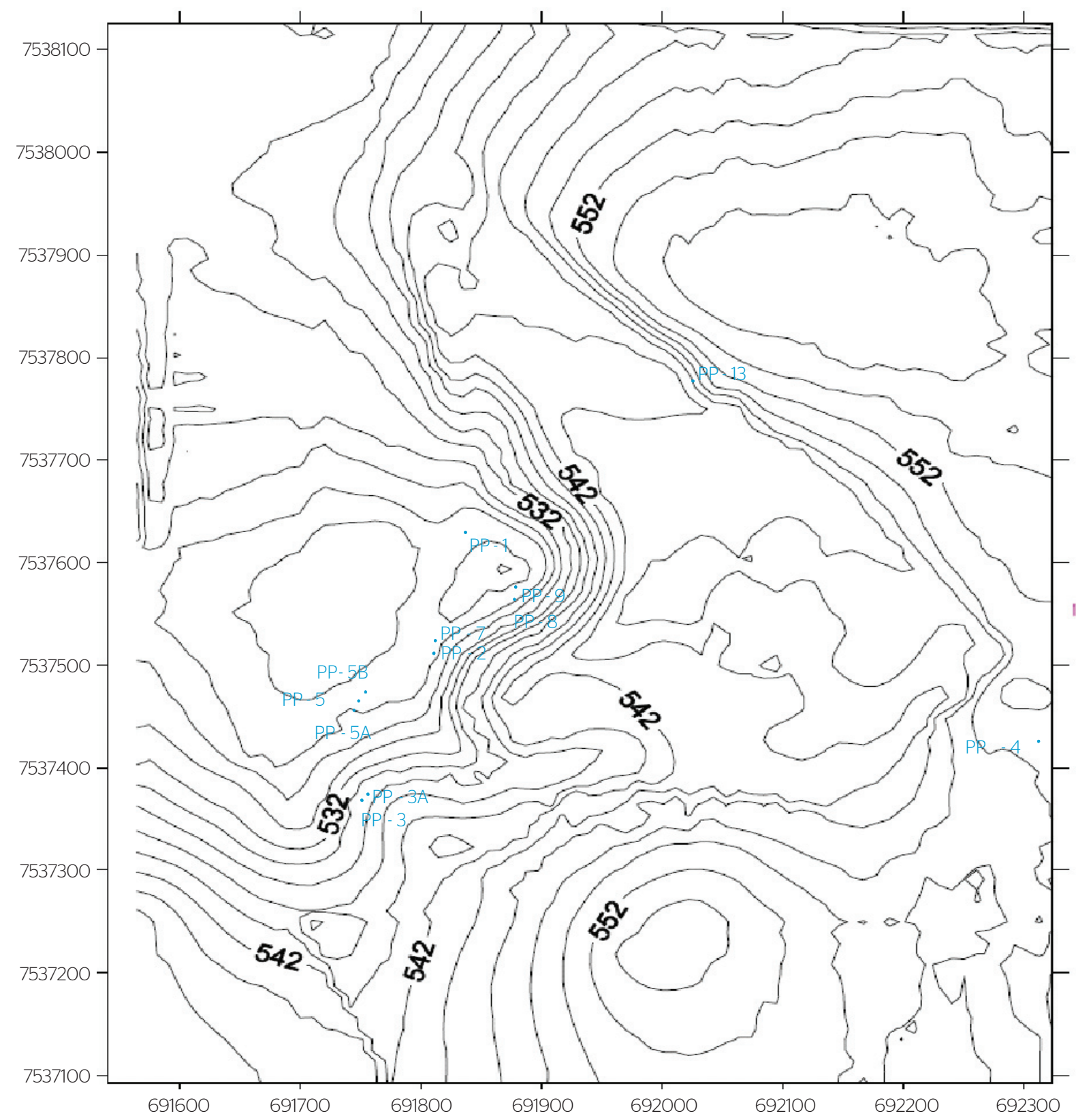

Figura 2 - Distribuição dos poços de monitoramento permanentes existentes na área do aterro de Bauru, em 2007, sobre coordenadas UTM. 


\section{RESULTADOS E DISCUSSÃO}

Descartando-se os poços que sofreram influência tanto da má manutenção, estiagem, inseridos em diferentes compartimentos hidrogeológicos como de fatores externos ao aterro, como presença de gado, etc., as Figuras 6 a 12 apresentam a variação dos seguintes parâmetros ao longo do tempo de monitoramento do aquífero freático local: nível d'água, $\mathrm{pH}, \mathrm{CE}, \mathrm{Ca}^{2+}, \mathrm{Cl}$, Fe total, $\mathrm{DQO}, \mathrm{NH}_{4}^{+}, \mathrm{Zn}^{2+}, \mathrm{Na}^{+}, \mathrm{K}^{+}$.

A partir da Figura 6, observa-se que os poços apresentaram a tendência de os níveis dágua ficarem mais profundos com o tempo, independentemente da estação (seca ou chuvosa) em que foi realizada a coleta. Essa tendência foi confirmada a cada campanha e algumas hipóteses não conclusivas foram levantadas: alteração climática, bombeamento de água por algum poço, ou influência da modificação de todo o meio em que os resíduos eram dispostos, com escavações diversas para uso do solo de cobrimento diário dos resíduos.

De acordo com a Figura 7, os valores de $\mathrm{pH}$ confirmaram a influência da acidez dos solos residuais e laterizados do Grupo Bauru. Contudo, as águas dos poços PP-5, PP-5A, PP-5B, PP-4, PP-10, PP-11 e PP-12 apresentaram valores de $\mathrm{pH}$ mais alcalinos, que, no caso dos quatro últimos poços, podem estar relacionados aos elevados teores de cálcio (muito presente no Arenito Bauru), ou à própria alcalinidade presente no chorume. Isso pode ser um indicativo da contaminação por chorume nesses seis poços, pois o poço PP-13 (de referência e com filtro instalado na mesma formação geológica) apresenta valores mais baixos, da ordem de 6, como esperado para esses solos. Com exceção da última campanha de

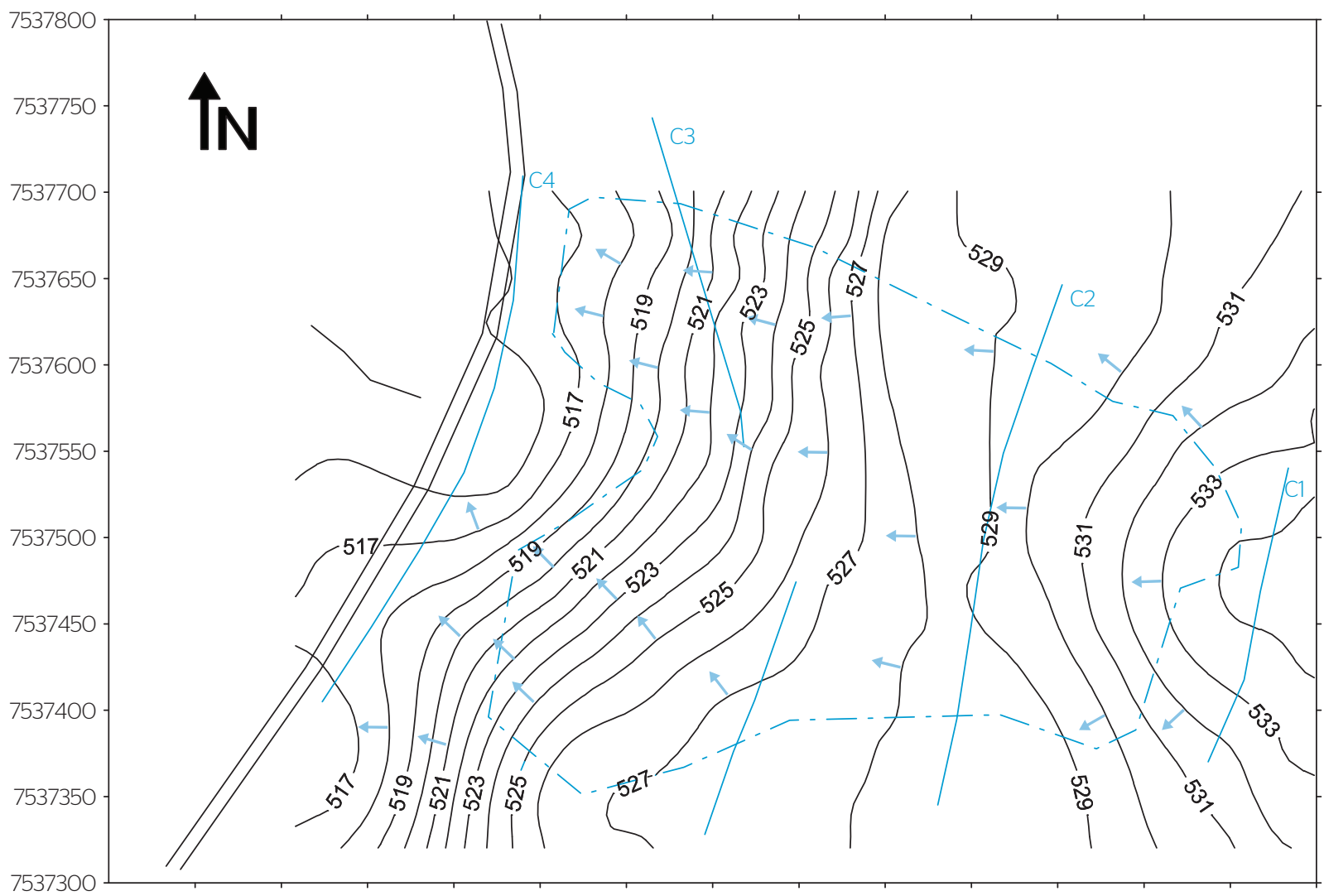

691650691700691750691800691850691900691950692000692050692100692150692200692250692300
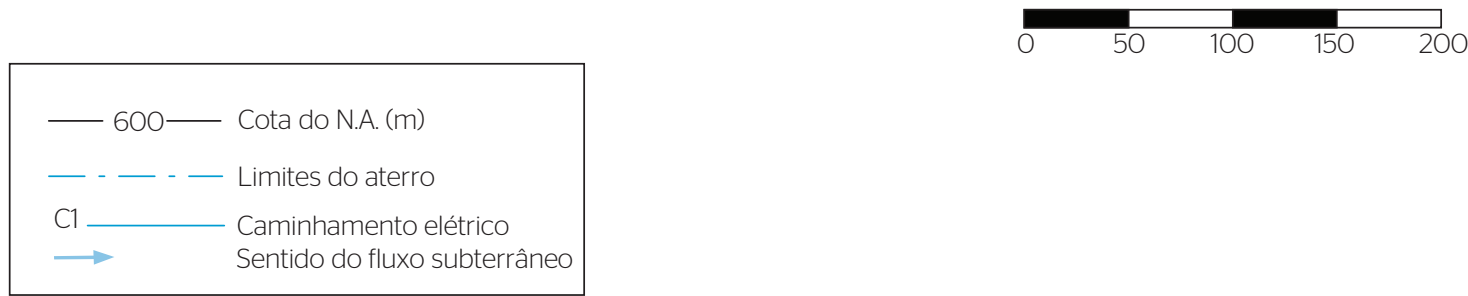

Fonte: Lago, 2004

Figura 3 - Mapa de fluxo subterrâneo definido através das sondagens elétricas verticais. 


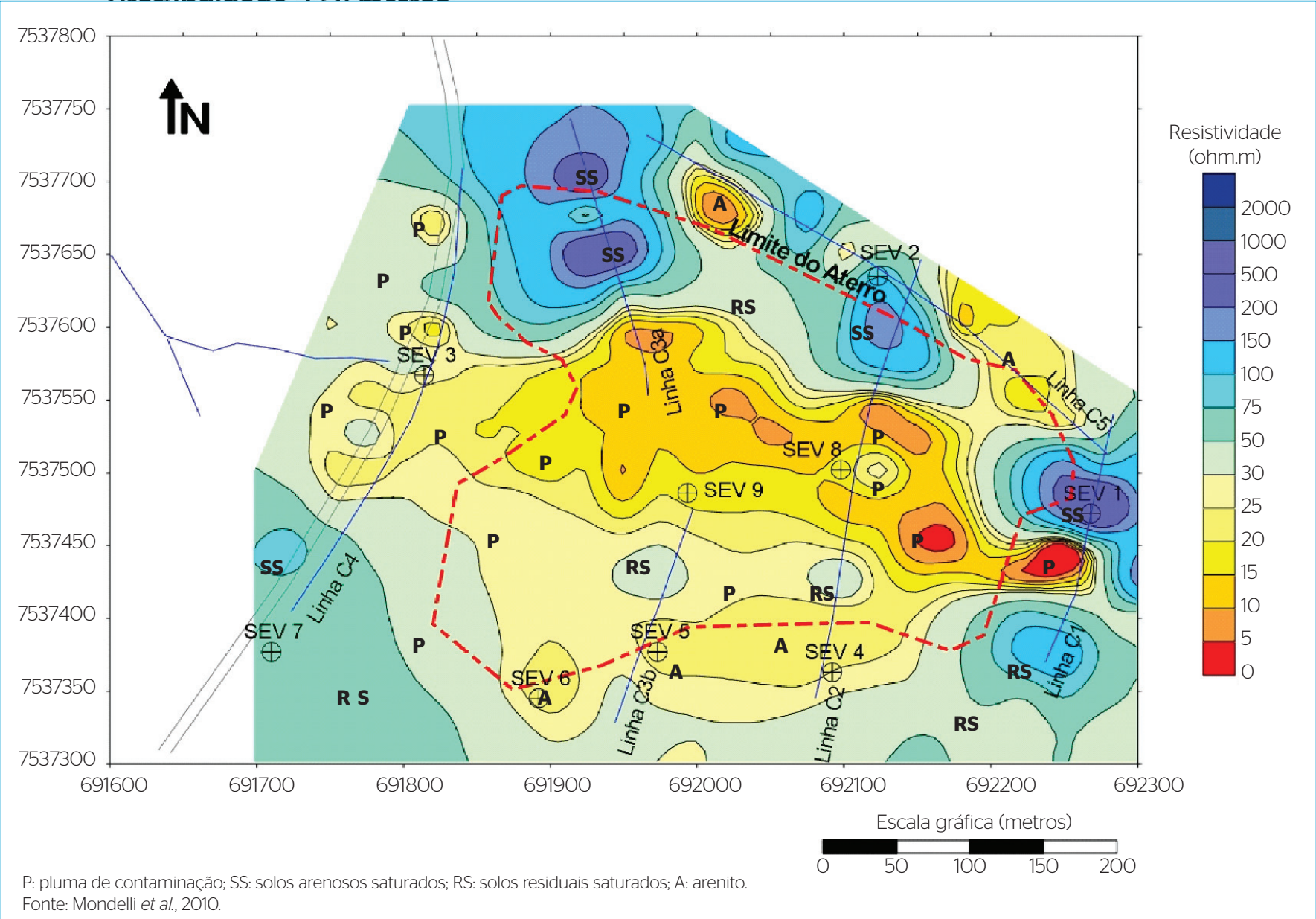

Figura 4 - Mapa de resistividade do nível teórico 22 m do aterro de resíduos sólidos de Bauru interpretado.

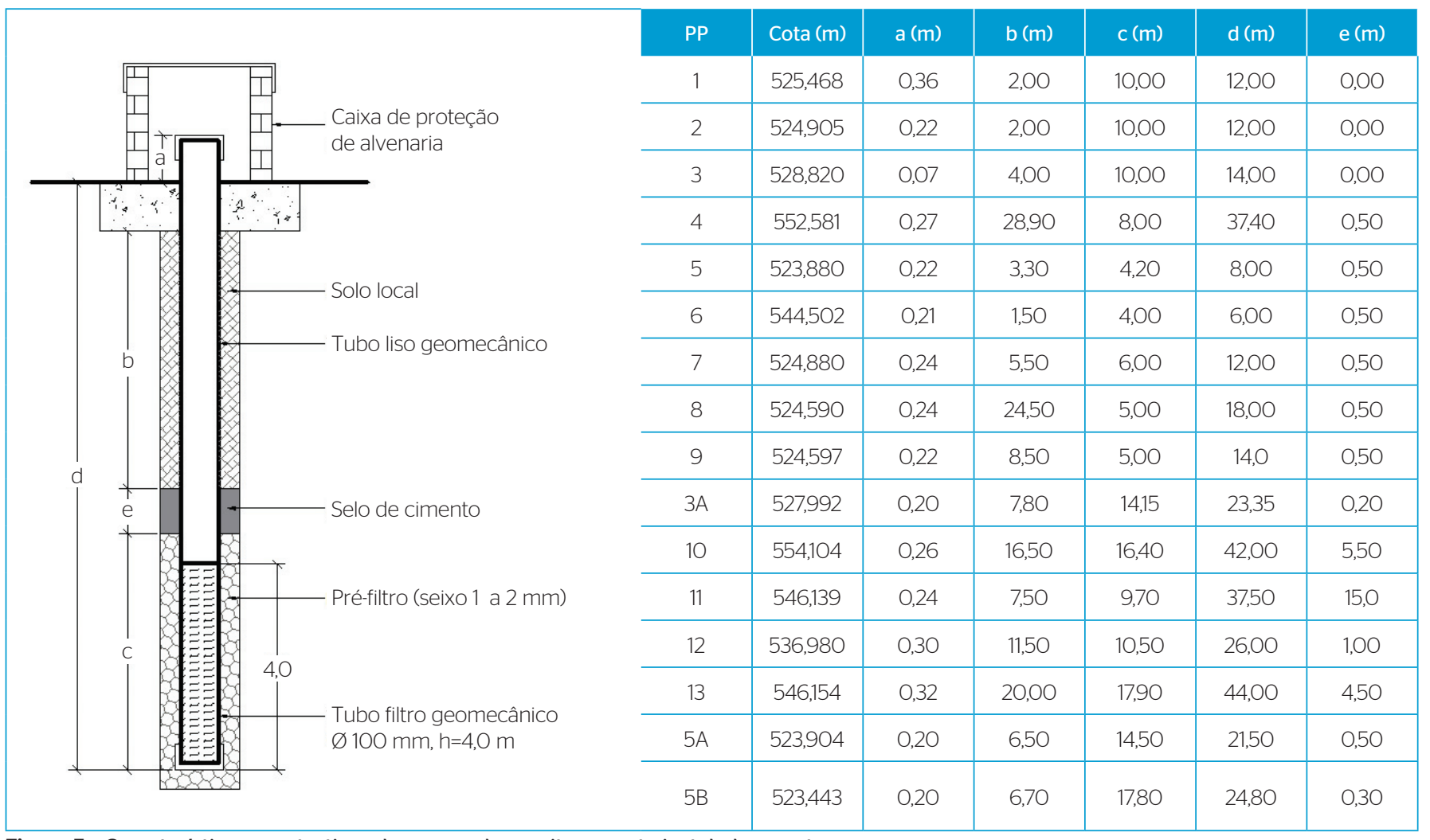

Figura 5 - Características construtivas dos poços de monitoramento instalados no aterro. 
coleta, realizada após a implantação das lagoas de chorume, observa-se na Figura 7 que os valores obtidos para o poço PP-11 estão acima dos demais poços e que o $\mathrm{pH}$ do poço PP-1 vem aumentando com o tempo.

Na tendência contrária dos demais poços, a CE dos poços PP-1 e PP-9 decresceu com o tempo (Figura 8), o que pode representar a mudança, com o tempo, dos locais de disposição e compactação de resíduos no aterro. Recorda-se que quando as análises foram iniciadas, em 2003, os resíduos estavam sendo dispostos a noroeste (próximo ao poço PP-1), passando para sudoeste e leste, causando uma piora na qualidade das águas dos poços PP-2, PP-7 e PP-4, respectivamente. Observa-se que os valores para esse parâmetro diminuíram substancialmente para todos os poços após a retirada das lagoas de chorume de sobre o aterro, em 2008.

Considerados um dos parâmetros mais representativos para avaliação da contaminação do aterro, os poços, de maneira geral, apresentaram valores médios acima de $300 \mathrm{mS} . \mathrm{cm}^{-1}$ para a CE, sendo que o esperado para o aquífero varia entre 100 e $280 \mathrm{mS} . \mathrm{cm}^{-1}$.

Com relação à evolução do teor de cloretos, também é observado um decaimento nos poços PP-1, PP-7 e PP-9, que depois voltam a crescer em 2008 (Figura 9). Os teores de cloretos (Figura 9) podem ser considerados baixos ou normais para a maioria dos poços, quando comparados com os níveis apresentados pelo chorume bruto (cerca de $4.000 \mathrm{mg} \cdot \mathrm{L}^{-1}$ ). Contudo, os cloretos comportam-se como íons traçadores, não ficando retidos no solo. Destaque para os poços PP-1 e PP-7, com teores mais elevados do que o esperado para o Aquífero Bauru (4,8 mg. $\left.\mathrm{L}^{-1}\right)$.
Observa-se, nas Figuras 2 e 7, que os valores de pH são menores a oeste do aterro, na região do poço PP-1, em que existe alto teor de ferro (laterização - Figura 12), e que aumentam gradualmente na direção sul. Os valores mais elevados encontrados para os poços PP-12, PP-11 e PP-10 podem ter sido influenciados pela maior presença de carbonatos no aquífero nessa região, mas não se descarta a hipótese de haver contaminação do aquífero para valores de $\mathrm{pH}$ acima de 6,5, valor considerado natural do aquífero com carbonatos.

Com exceção dos poços PP-5A e PP-5B, localizados na região de aluviões (Figura 2), os demais apresentam elevadas concentrações de ferro (Figura 10), devido à presença desse elemento nos solos lateríticos. Contudo, sugere-se atenção e continuidade do monitoramento em especial dos poços PP-1, PP-4 e PP-7. É difícil diagnosticar a situação em que o íon se encontra no aquífero, se reduzido, complexado ou apenas dissolvido. Sabe-se, por exemplo, que o ferro e o manganês podem aparecer em estado reduzido $\left(\mathrm{Fe}^{2+}\right.$ e $\left.\mathrm{Mn}^{2+}\right)$ ou oxidado $\left(\mathrm{Fe}^{3+}\right.$ e $\left.\mathrm{Mn}^{4+}\right)$, dependendo do meio e da distância em que a pluma se encontra do aterro de resíduos. Christensen et al. (2001) apresentam um zoneamento esquemático para as reações de oxirredução do ferro e do manganês para um aquífero aeróbico. A tendência geral é que o chorume reduzido apresente condições metanogênicas próximas ao aterro, reduzidas no meio e oxidadas na periferia da pluma. Para a realização desses tipos de monitoramentos, análises químicas capazes de identificar as diferentes condições em que os íons se encontram (procedimentos que

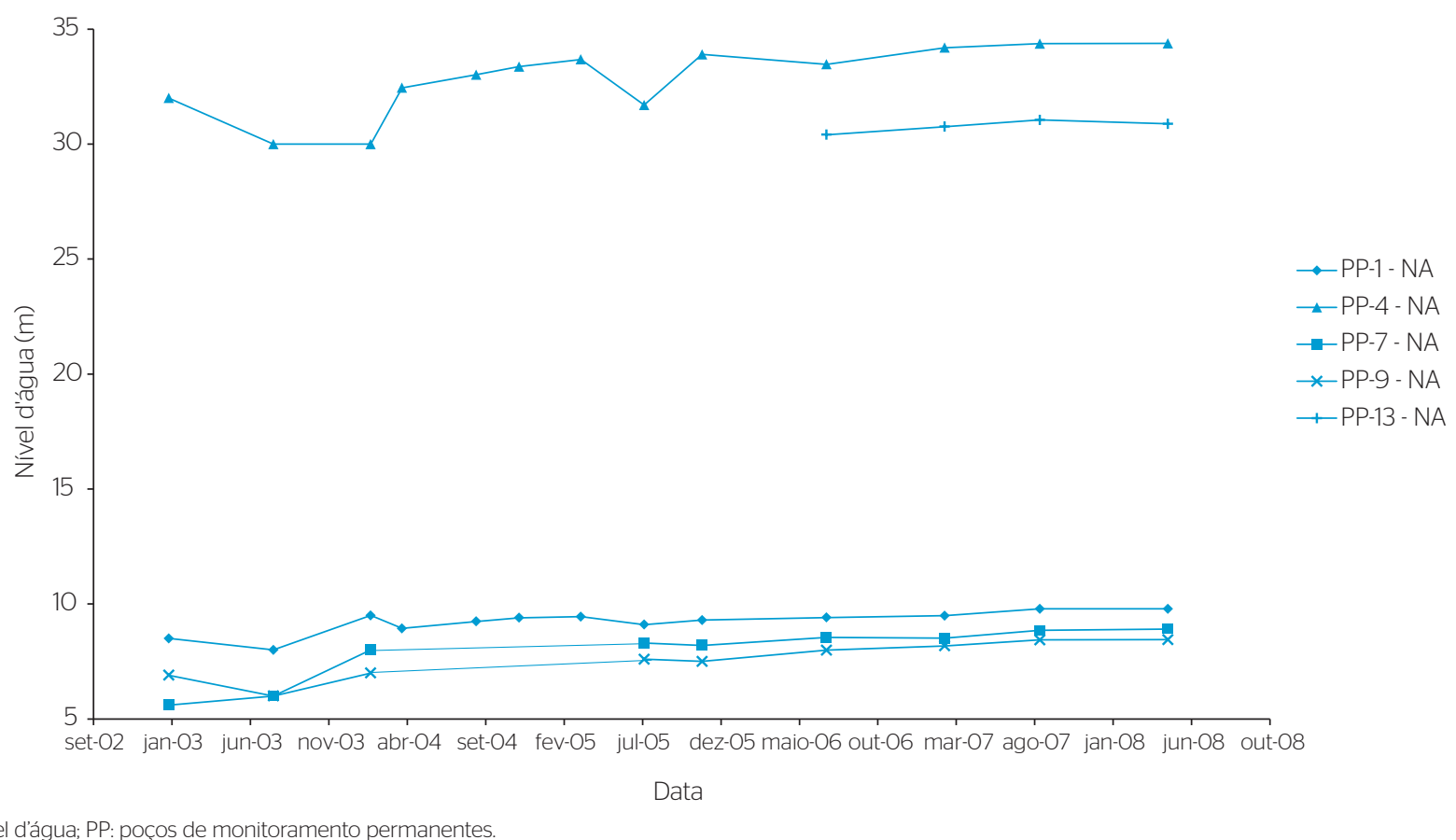

NA: nível d'água; PP: poços de monitoramento permanentes.

Figura 6 - Variação da profundidade do nível d'água ao longo do tempo. 


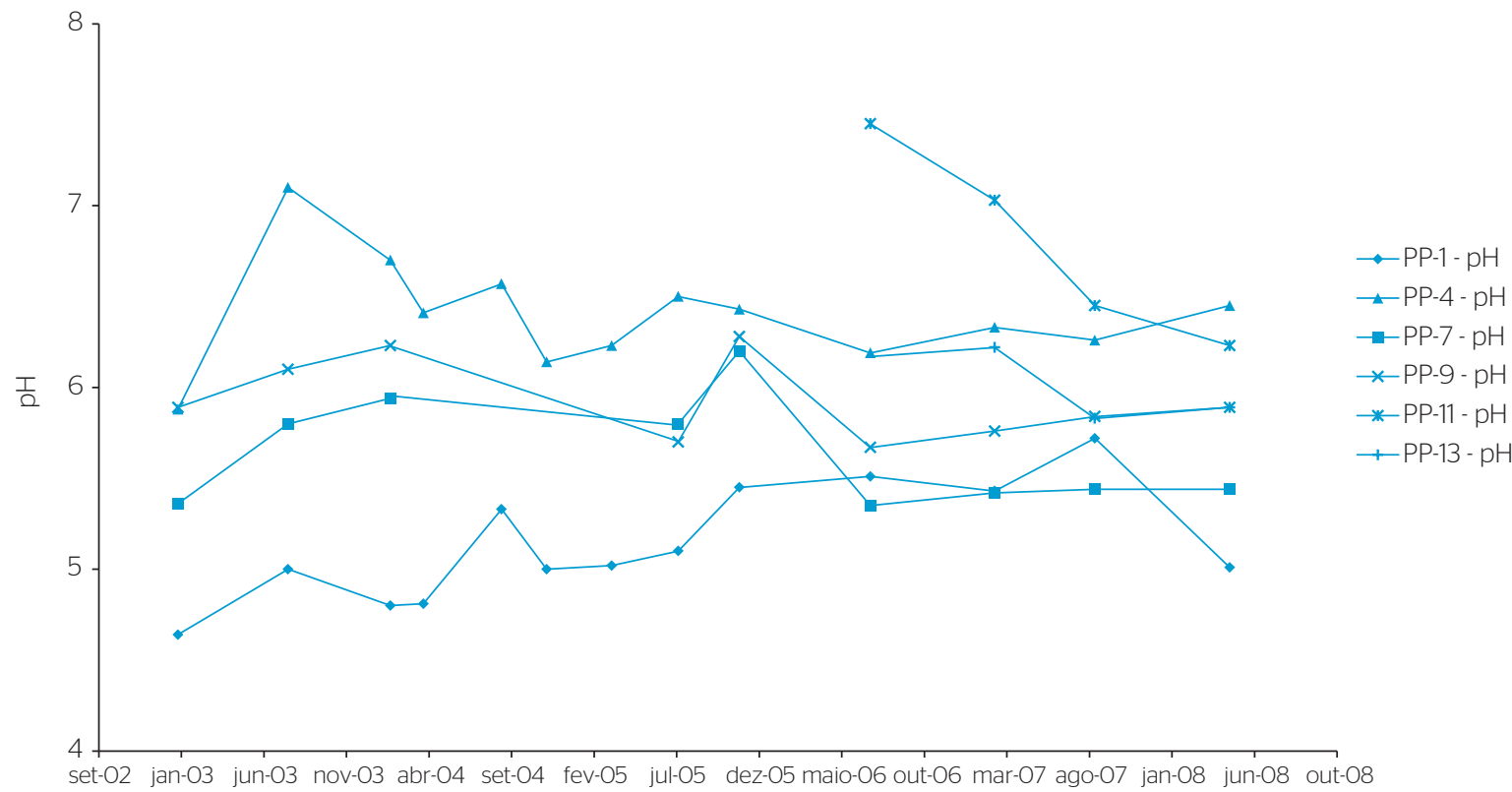

Data

PP: poços de monitoramento permanentes.

Figura 7 - Variação do pH ao longo do tempo.

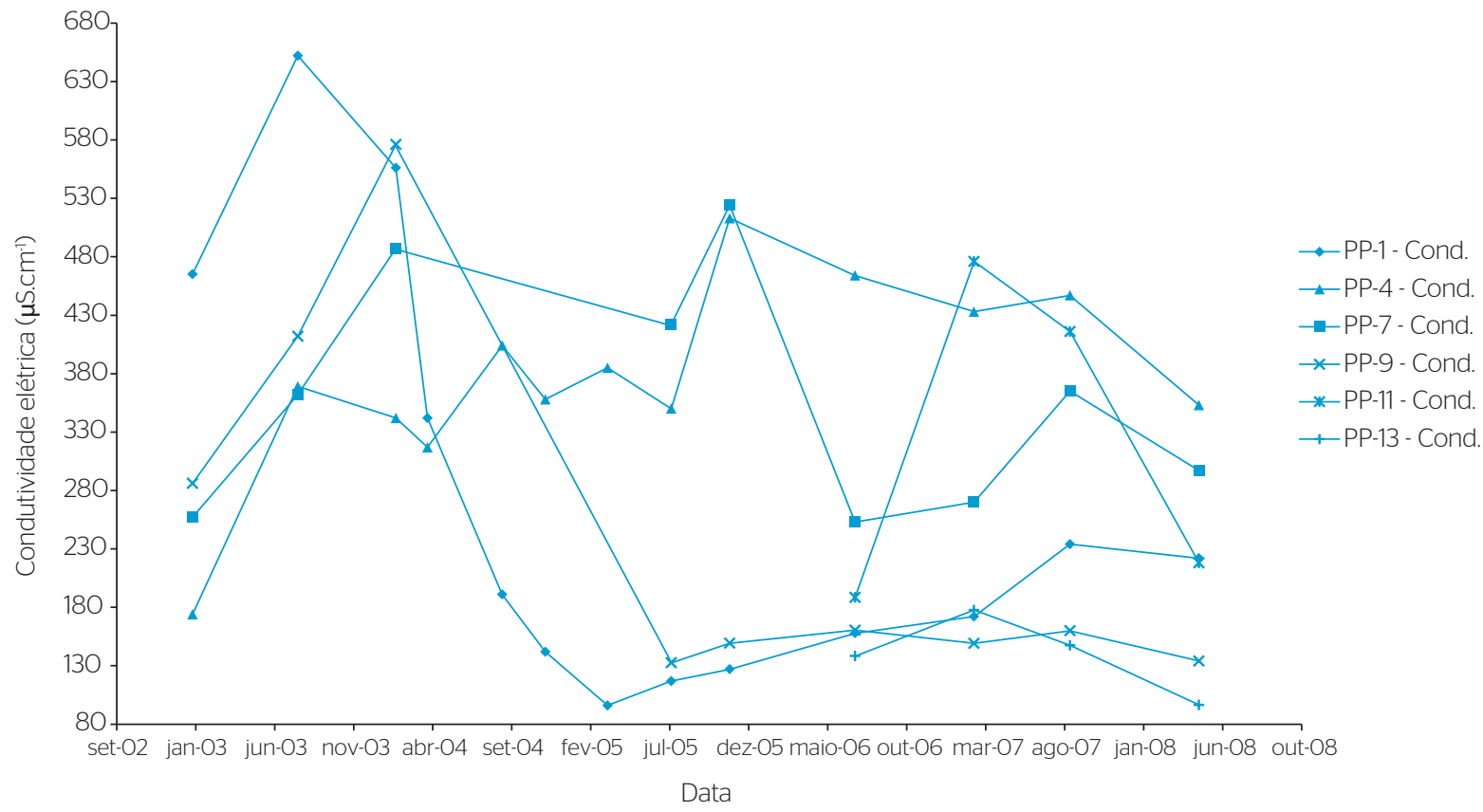

Cond: condutividade elétrica; PP: poços de monitoramento permanentes.

Figura 8 - Variação da condutividade elétrica ao longo do tempo. 


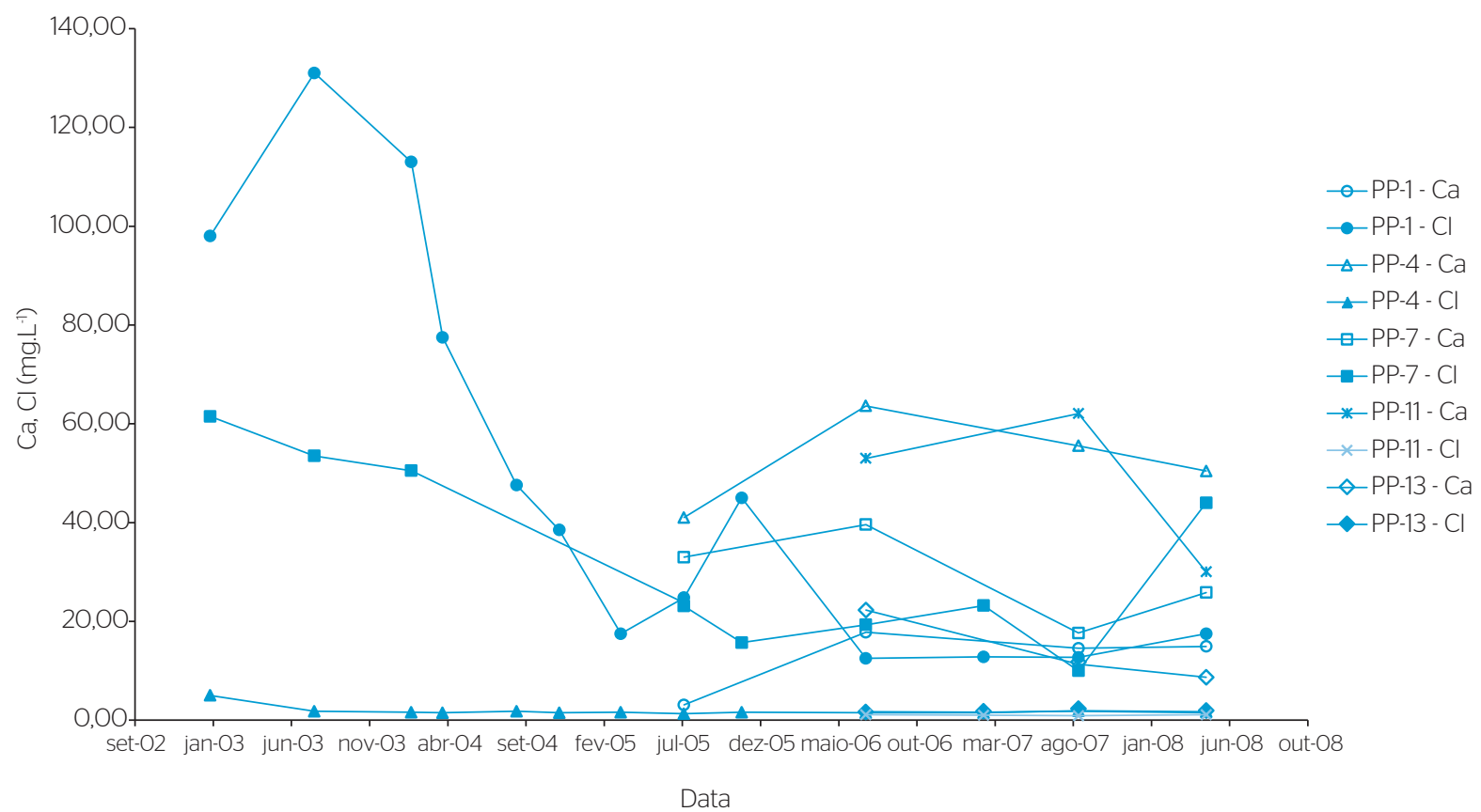

Ca: cálcio; Cl: cloretos.

Figura 9 - Variação das concentrações de cálcio e cloretos ao longo do tempo.

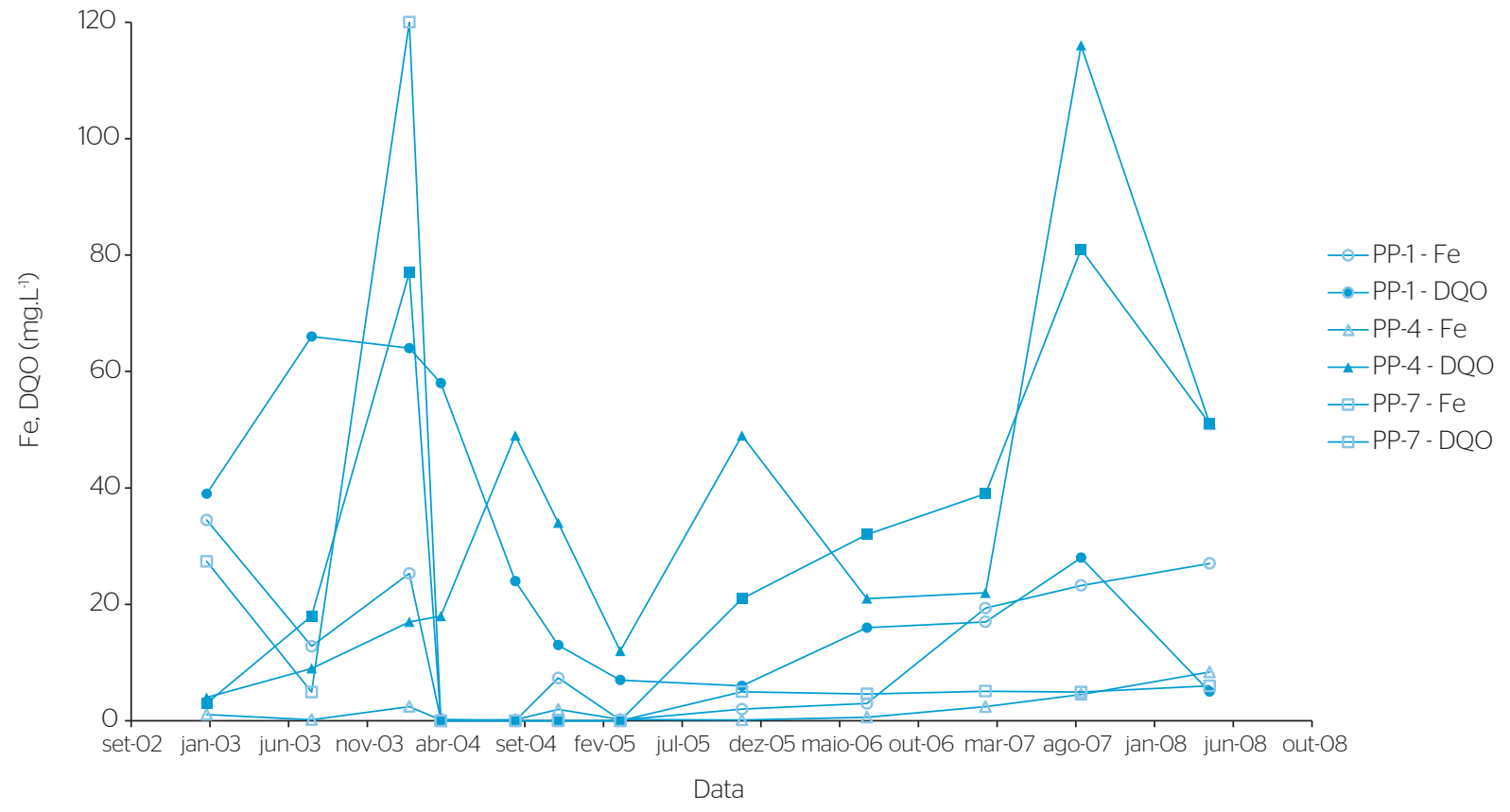

Fe: ferro total; DQO: demanda química de oxigênio; PP: poços de monitoramento permanentes.

Figura 10 - Variação das concentrações de ferro total e demanda química de oxigênio ao longo do tempo. 


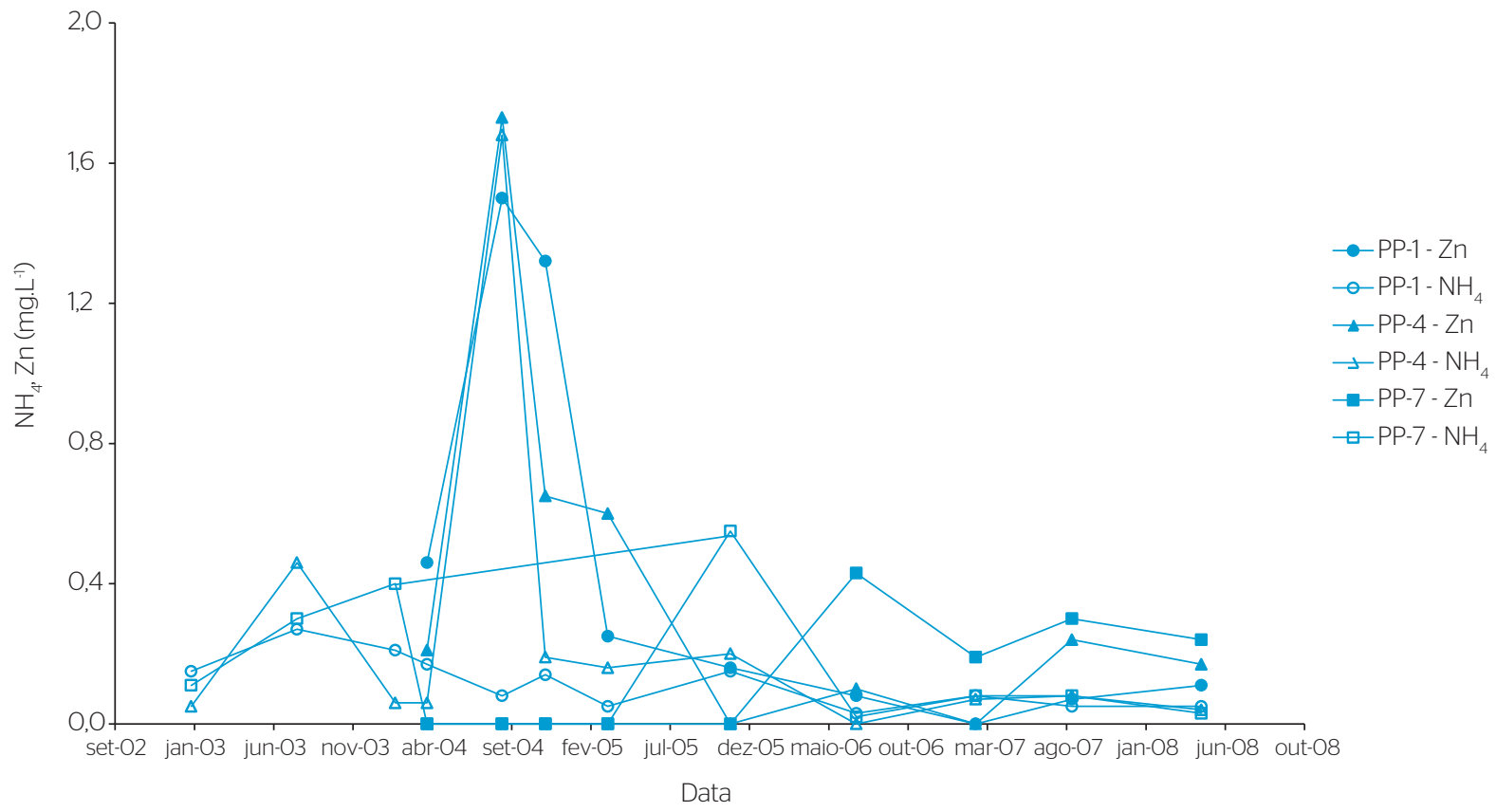

$\mathrm{NH}_{4}$ : nitrogênio amoniacal; Zn: zinco; PP: poços de monitoramento permanentes.

Figura 11 - Variação das concentrações de nitrogênio amoniacal e zinco ao longo do tempo.

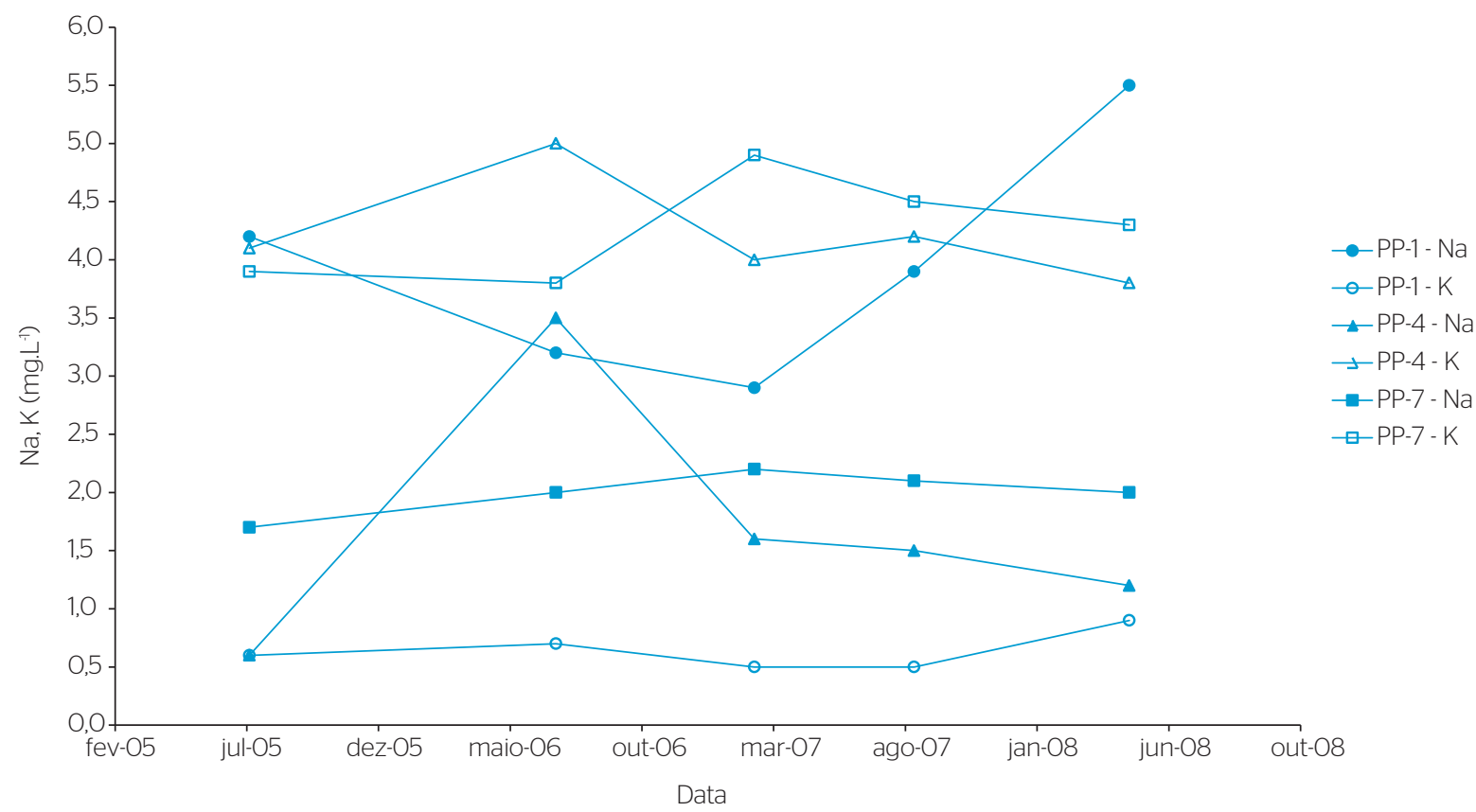

Na: sódio; K: potássio; PP: poços de monitoramento permanentes.

Figura 12 - Variação das concentrações de sódio e potássio ao longo do tempo. 
têm um elevado custo) devem ser realizadas. Para o aterro estudado, foi monitorado o ferro total, ficando difícil a distinção entre o $\mathrm{Fe}^{2+} \mathrm{e}$ $\mathrm{Fe}^{3+}$, assim como a sua fonte (se do solo ou da pluma).

Presente em grande quantidade no chorume, o nitrogênio amoniacal (Figura 11) não apresentou concentrações maiores que o padrão de potabilidade (1,5 mg. $\left.\mathrm{L}^{-1}\right)$. Observa-se que alguma anomalia pode ter ocorrido em 2004 na água amostrada do poço PP-4, acompanhado de maiores teores de Zn no mesmo período para o poço em questão e para o PP-1. Também houve decréscimo desse parâmetro em todos os poços após a retirada, em 2008, das lagoas de chorume que operam sobre o aterro.

Entre os metais pesados investigados, o zinco é o que aparece com mais frequência na água dos poços, apesar de não ultrapassar o limite de potabilidade (5 mg.L $\mathrm{L}^{-1}$ ). Apesar de esse elemento poder fazer parte da constituição natural do solo ou da rocha, atenção deve ser dada aos poços PP-4, PP-7, PP-11 e PP-13. Na Figura 11 observa-se uma tendência de decréscimo nas concentrações para o poço PP-1 e o contrário para os poços PP-4 e PP-7.

Apesar de o sódio e o potássio estarem presentes nos minerais constituintes do solo, também está presente em elevadíssimas concentrações no chorume. As concentrações de $\mathrm{Na}^{+} \mathrm{e} \mathrm{K}^{+}$podem ser consideradas baixas, apesar de os valores de K estarem próximos do limite do Aquífero Bauru $\left(6,4 \mathrm{mg} . \mathrm{L}^{-1}\right)$. A Figura 12 apresenta a variação da concentração desses dois metais alcalinos no tempo que, aparentemente, parece estar razoavelmente constante, com exceção do aumento de sódio verificado para o poço PP-1. Sódio e cloretos são caracterizados por serem íons traçadores e presentes em grande quantidade no chorume. Com base nos resultados dos ensaios de laboratório realizados por Mondelli (2008), os coeficientes de dispersão e de retardamento obtidos para o sódio e cloretos foram praticamente iguais, com o sódio apresentando um retardamento apenas um pouco maior. Observa-se que as maiores concentrações de $\mathrm{Na}^{+}$e Cl- encontram-se a jusante, no sentido do fluxo subterrâneo, assim como o ferro, presente em grandes concentrações no solo de alteração e no colúvio e encontrado nas águas do poço PP-1. De qualquer forma, as concentrações são muito pequenas quando comparadas com o chorume e os padrões de qualidade estabelecidos. Acredita-se que haja uma grande influência da diluição nas concentrações desses parâmetros, principalmente devido a sua grande capacidade de dispersão nos solos locais.

A Figura 13 apresenta a relação DBO/DQO para todos os poços construídos na área, ao longo do tempo de monitoramento. De maneira geral, como os poços apresentam baixos valores de $\mathrm{DBO}_{5}-$ com exceção dos poços PP-1, PP-4, PP-5, PP-6, PP-7 e PP-13, que ultrapassaram o limite de qualidade estabelecido (5 mg.L ${ }^{-1}$, segundo CONAMA, 2005) em algumas campanhas - e valores elevados de DQO, como PP-1, PP-2, PP-4, PP-5, PP-6, PP-7, PP-9, PP-10 e PP-13, tanto a jusante como montante do fluxo subterrâneo, as relações DBO/DQO obtidas são pequenas. Como a DQO é a parcela de matéria orgânica pouco susceptível à decomposição por ação microbiana e susceptível à oxidação, nas condições ambientais ou em condições preestabelecidas (QASIM \& CHIANG, 1994; CHAPMAN \& KIMSTACH, 1996). Já a $\mathrm{DBO}_{5}$ representa a parcela de matéria orgânica

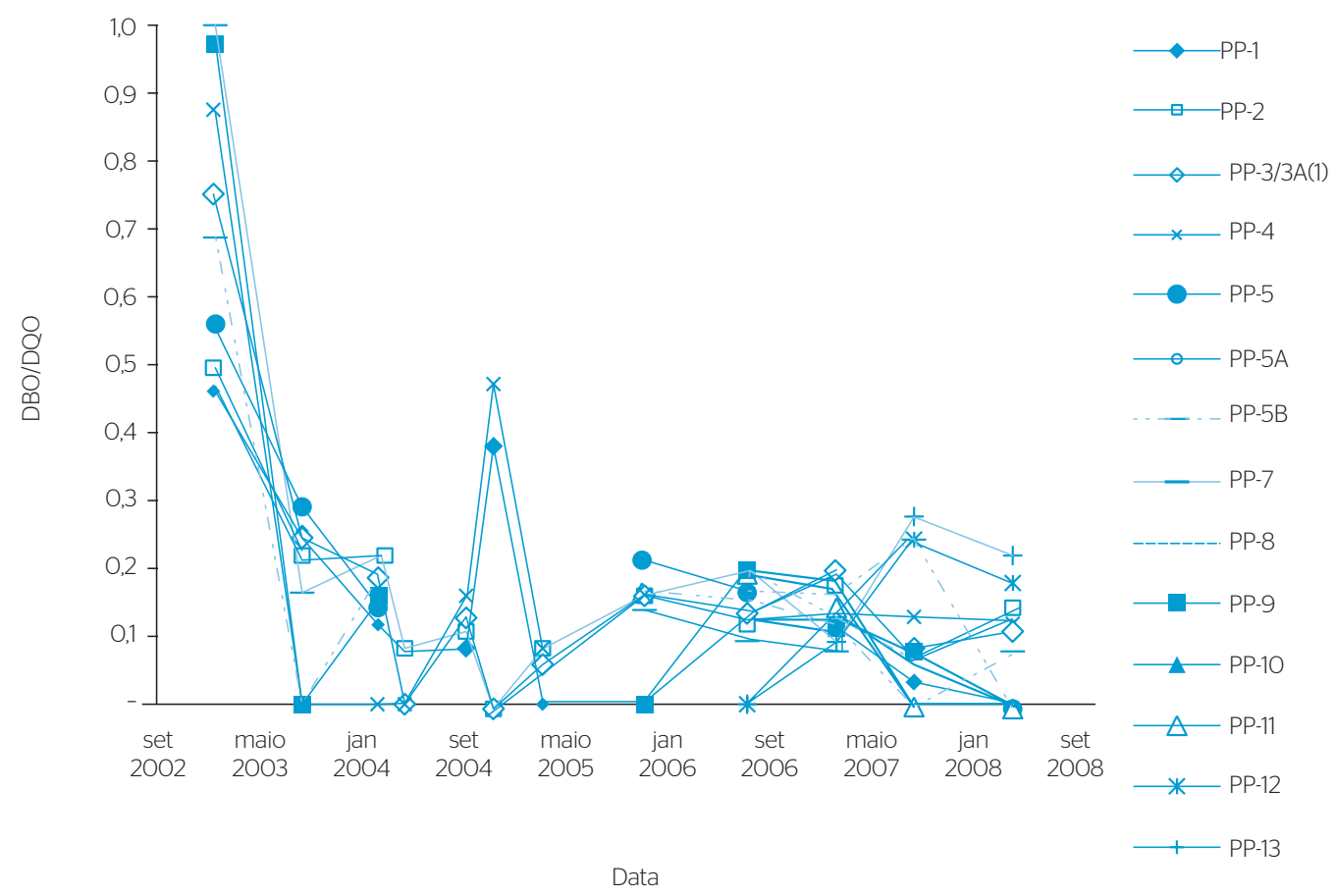

DBO: demanda biológica de oxigênio; DQO: demanda química de oxigênio; PP: poços de monitoramento permanentes.

Figura 13 - Resultados obtidos para a relação demanda biológica de oxigênio/demanda química de oxigênio para a área estudada. 
de um efluente susceptível à decomposição por ação microbiana nas condições ambientais. A existência e a magnitude da matéria orgânica biodegradável, em relação à parcela não biodegradável, são avaliadas por meio do cálculo da relação entre a DBO e DQO em concentração relativa ao mesmo período de tempo. Um efluente terá mais características de biodegradabilidade quanto maior for sua relação DBO/DQO. Desse modo, sabe-se que a relação DBO/DQO do chorume diminui com sua idade in situ, devido a sua decomposição (QASIM \& CHIANG, 1994). A Figura 13 apresenta justamente esse comportamento. Observa-se que a existência de matéria orgânica biodegradável era maior na água subterrânea em janeiro de 2003, quando existiam frentes de disposição de resíduos nas partes central e sul do aterro, que era mais novo, principalmente na região do poço PP-12. Após a retirada das lagoas de chorume de cima do aterro, em abril 2008, observou-se uma diminuição da relação DBO/DQO, principalmente a leste do aterro (poço PP-4), indicando que a matéria orgânica biodegradável, assim como outros parâmetros, teve valores reduzidos na região do poço PP-4, que mesmo a montante do fluxo subterrâneo sofria influência das lagoas de chorume localizadas sobre o aterro. A relação DBO/DQO mostra-se como uma informação muito importante na avaliação da idade e da caracterização da(s) pluma(s) de contaminação do aterro e deve continuar sendo monitorada em conjunto com as atividades de superfície e de operação do aterro. Observa-se que tal relação varia de acordo com a posição da frente de disposição de resíduos, caracterizando a idade do chorume que está sendo ou foi gerado pelos resíduos.

Em resumo, se forem tratados como padrão de consumo humano, os seguintes parâmetros estão acima ou fora dos limites adotados pela CETESB (2014): pH, fosfato total, DBO, Pb, Fe e Cr. Com base na experiência adquirida no local ao longo das diversas campanhas de monitoramento realizadas de 2003 a 2008, são aqui sugeridos valores de referência para a área, a fim de nortear futuras campanhas de monitoramento do aquífero freático local: $\mathrm{pH}<6,5 ; \mathrm{CE}<200 \mathrm{mS} . \mathrm{cm}^{-1} ; \mathrm{Cl}^{-}<20 \mathrm{mg} . \mathrm{L}^{-1} ; \mathrm{C} . \mathrm{O} .<2 \mathrm{mg} . \mathrm{L}^{-1}$; $\mathrm{SO}_{4}<10 \mathrm{mg}$. $\mathrm{L}^{-1} ;$ sulfatos e sulfetos ausentes; $\mathrm{NH}_{3}<0,1 \mathrm{mg} . \mathrm{L}^{-1} ; \mathrm{NO}_{4}<5 \mathrm{mg}$. $\mathrm{L}^{-1}$; $\mathrm{NO}_{2}<0,01 \mathrm{mg} \cdot \mathrm{L}^{-1} ; \mathrm{N}<2 \mathrm{mg} . \mathrm{L}^{-1} ; \mathrm{PO}_{4}<0,15 \mathrm{mg} . \mathrm{L}^{-1} ; \mathrm{DQO}<25 \mathrm{mg}$. $\mathrm{L}^{-1}$; $\mathrm{DBO}<5 \mathrm{mg} . \mathrm{L}^{-1}$; coliformes e E. coli ausentes; $\mathrm{Zn}<0,1 \mathrm{mg} . \mathrm{L}^{-1} ; \mathrm{Pb}, \mathrm{Ni}, \mathrm{Cd}$ e Cr ausentes; $\mathrm{Fe}<20$ mg. $\mathrm{L}^{-1} ; \mathrm{Na}<7$ mg. $\mathrm{L}^{-1} ; \mathrm{K}<7 \mathrm{mg} . \mathrm{L}^{-1} ; \mathrm{Ca}<50 \mathrm{mg} . \mathrm{L}^{-1}$.

\section{CONCLUSÕES}

Após as diversas campanhas de coleta de água nos poços de monitoramento instalados no entorno do aterro estudado, conclui-se que:

- a verificação da existência da contaminação depende da definição dos valores de referência (background) e do conhecimento das características naturais do aquífero. Uma vez que o monitoramento foi iniciado após a construção do aterro, não foi possível estabelecer preliminarmente estes valores;

- o conhecimento sobre fluxo subterrâneo deve ser definido previamente por intermédio da análise das características topográficas e hidrogeológicas da área, empregando diferentes técnicas de investigação;

- o entendimento sobre o que está acontecendo em superfície - como cobertura existente ou não, drenagem, posição onde os resíduos estavam sendo depositados e tipo de contaminantes dispostos em determinada época - pode explicar o que está dissolvido nas águas subterrâneas. Além disso, como não estão localizadas no ponto hidráulico crítico da área, a evolução dessas plumas de contaminação depende da presença ou não de chuvas recentes, da cobertura dos resíduos, da superposição de gradientes (natural e de chorume) e também da capacidade de sorção dos solos presentes em estado saturado e não saturado;

- os poços de monitoramento confirmam que são uma técnica excelente de investigação geoambiental. No entanto, em solos residuais e em rochas características de regiões tropicais, devido à dificuldade de perfuração e à presença do nível d'água em grandes profundidades, as técnicas de perfuração precisam ser melhoradas, normalizadas e adequadas para as condições brasileiras. A utilização de poços multiníveis e cravadores hidráulicos e/ou sônicos, que não necessitam de água durante a perfuração, assim como uma caracterização mais detalhada da litologia, e com selo de bentonita ao longo de todo o perfil dos poços, deixando apenas o(s) filtro(s) livre(s), com comprimentos máximos de $2 \mathrm{~m}$, podem melhorar a qualidade e diminuir a diluição das amostras de água;

- a instalação de piezômetros sobre os resíduos poderia auxiliar no monitoramento do nível de chorume dentro do aterro e, assim, possibilitar a realização de balanços hídricos e estudos sobre a influência e a infiltração real de chorume no aquífero, corroborando os resultados obtidos a partir de técnicas indiretas ou mesmo de interpolação; - nem sempre a escolha do local de implantação de poços de monitoramento com base apenas na topografia e no fluxo subterrâneo preferencial cumpre o objetivo desejado para uma investigação geoambiental, podendo haver influência da forma, tempo e locais de disposição, além da complexa hidrogeologia ou mesmo de alterações provocadas na mesma pela presença do aterro;

- como a influência do aterro de resíduos sobre o aquífero freático local foi detectada, foram sugeridos parâmetros para continuidade do monitoramento do aquífero local, cuja recuperação e atenuação deverão ocorrer com o encerramento das atividades do aterro.

\section{AGRADECIMENTOS}

Os autores agradecem à Fundação de Amparo à Pesquisa do Estado de São Paulo (FAPESP), à Coordenação de Aperfeiçoamento de Pessoal de Nível Superior (CAPES) e ao Conselho Nacional de Desenvolvimento Tecnológico (CNPq), pelo financiamento de suas pesquisas. Agradecem também à Empresa Municipal de Desenvolvimento Urbano de Rural de Bauru (EMDURB-Bauru), por ter autorizado a realização desta pesquisa. 


\section{REFERÊNCIAS}

ABNT - Associação Brasileira de Normas Técnicas. (1997) ABNT NBR 13895/1997: Construção de Poços de Monitoramento e Amostragem Procedimento, $21 \mathrm{p}$

ABNT - Associação Brasileira de Normas Técnicas. (2007) ABNT NBR 15495-1/2007: Poços de monitoramento de águas subterrâneas em aquíferos granulados. Parte 1: Projeto e construção, 25 p.

ADEREMI, A.O.; ORIAKU, A.V.; ADEWUMI, G.A.; OTITOLOJU, A.A. (2O11) Assessment of groundwater contamination by leachate near a municipal solid waste landfill. African Journal of Environmental Science and Technology, v. 5, n. 11, p. 933-940.

APHA - AMERICAN PUBLIC HEALH ASSOCIATION. (1995) Standard Methods for the Examination of Water and Wastewater.. 19th ed. p. 3-1-3-2.

BOLINELLI JUNIOR, H.L., MONDELLI, G;; GIACHETI, H.L.; DE MIO, G.; PEIXOTO, A.S.P. (2005) Piezocone de resistividade na investigação do subsolo: Execução, interpretação e exemplos de aplicação. In: Congresso Brasileiro de Geologia de Engenharia e Ambiental, 11 2005, Florianópolis-SC. CD-ROM.

BRASIL. Ministério da Saúde. (2004) Portaria no 518, de 26 de março de 2004. Estabelece os procedimentos e responsabilidades relativos ao controle e vigilância da qualidade da água para consumo humano e seu padrão de potabilidade, e dá outras providências. Brasília: Ministério da Saúde.

COMPANHIA AMBIENTAL DO ESTADO DE SÃO PAULO - CETESB. (2004) Relatório de qualidade das águas subterrâneas no Estado de São Paulo 2001-2003. São Paulo: CETESB. Série Relatórios. 103 p.+anexos.

COMPANHIA AMBIENTAL DO ESTADO DE SÃO PAULO - CETESB. (2005) Relatório de estabelecimento de valores orientadores para solos e águas subterrâneas no Estado de São Paulo. São Paulo: CETESB. 73 p.

COMPANHIA AMBIENTAL DO ESTADO DE SÃO PAULO - CETESB. (2014) Decisão de Diretoria O45/2014/E/C/l, de 20-02-2014. Dispõe sobre a aprovação dos Valores Orientadores para Solos e Águas Subterrâneas no Estado de São Paulo - 2014, em substituição aos Valores Orientadores de 2005 e dá outras providências. São Paulo: CETESB.

CHAPMAN, D. \& KIMSTACH, V. (1996) Selection of water quality variables. In: CHAPMAN, D. (Ed.) Water quality assessments: a guide to the use of biota, sediments and water in environmental monitoring. $2^{\text {nd }}$ ed. London: UNESCO/WHO/UNEP, E\&FN. Spon and Chapman \& Hall. Chapter 3.

CHRISTENSEN, T.H.; KJELDSEN, P.; BJERG, P.L.; JENSEN, D.L.; CHRISTENSEN, J.B.; BAUN, A.; ALBRECHTSEN, H.J.; HERON, G. (2001) Biogeochemistry of landfill leachate plumes. Applied Geochemistry, v. 16, p. 659-718.

CONSELHO NACIONAL DO MEIO AMBIENTAL - CONAMA. (2005) Dispõe sobre a classificação dos corpos de água e diretrizes ambientais para o enquadramento, bem como estabelece as condições e padrões de lançamento de efluentes, e dá outras providências. Resolução no 357, de 17 de março de 2005. Alterada pela Resolução 410/2009 e pela Resolução 430/2011. Brasília: CONAMA.

CONSELHO NACIONAL DO MEIO AMBIENTAL - CONAMA. (2008) Dispõe sobre a classificação dos corpos de água e diretrizes ambientais para o enquadramento das águas subterrâneas e dá outras providências. Resolução no 396, de 04 de abril de 2008. Brasília: CONAMA.
DAVIES, M.P. \& CAMPANELLA, R.G. (1995) Environmental site characterization using in-situ testing methods. In: Canadian Geotechnical Conference, 48 1995, Vancouver-BC.

DE MIO, G.; GIACHETI, H.L.; STEVANATO, R.; GOIS, J.R.; FERREIRA, F.J.F. (2005) Investigação de intrusão de água salgada em aqüífero superficial a partir de medidas de resistividade elétrica. Solos e Rochas, v. 28, p. 249-260

DIAS, G.N.; DIAS, H.S.R.; BRAGA, K.C.S.; RUFFEIL, L.A. (2013) Contaminação do lençol freático por derivados de hidrocarbonetos: uma análise sobre um vazamento ocorrido em Belém/PA. Geotecnia, n. 129, p. 117-127.

FIPAI (1992) Aterro Sanitário da Cidade de Bauru-SP. EIA-RIMA (Relatório de Impacto Ambiental - Relatório de Impacto do Meio Ambiente. São Carlos Fundação para o Incremento da Pesquisa e do Aperfeiçoamento Industrial.

GANDOLFO, O.C.B.; MONDELLI, G.; BLANCO, R.G. (2012) The use of geophysical methods to investigate a contaminated site with organochlorine. In: International Conference on Geotechnical and Geophysical Site Characterization (ISC'4), 42012, Porto de Galinhas, Brazil.

INSTITUTO VIDÁGUA. (2004) Disponível em: <http://www.vidagua.org br/imagens/ImgBauru/mapa_d5.gif>. Acesso em: 14 de fev. 2004.

INTERSTATE TECHNOLOGY \& REGULATORY COUNCIL - ITRC. (2003) Technical and Regulatory Guidance for the Triad Approach: A New Paradigm for Environmental Project Management. Interstate Technology \& Regulatory Council. Sampling, Characterization and Monitoring Team, USA

LAGO, A.L. (2004) Aplicação Integrada de Métodos Geofísicos em Área de Disposição de Resíduos Sólidos Urbanos em Bauru - SP. Dissertação (Mestrado) - Instituto de Astronomia, Geofísica e Ciências Atmosféricas da Universidade de São Paulo, São Paulo.

LOPES, A.A. (2007) Estudo da Gestão Integrada dos Resíduos Sólidos Urbanos na Bacia Tietê-Jacaré. Tese (Doutorado) - Escola de Engenharia de São Carlos, Universidade de São Paulo, São Carlos.

MACEDO, L.S.; NOGUEIRA, T. P.; DE PAULA, M. N.; MONDELLI, G. YOSHIKAWA, N.K. (2011) Monitoramento de hexaclorociclohexano $(\mathrm{HCH})$ em águas subterrâneas. In: Congresso Brasileiro de Engenharia Sanitária e Ambiental, 26 2011, Porto Alegre-RS.

MONDELLI, G. (2008) Integração de diferentes técnicas de investigação para avaliação da poluição e contaminação de uma área de disposição de resíduos sólidos urbanos. Tese (Doutorado) - Escola de Engenharia de São Carlos, Universidade de São Paulo, São Carlos.

MONDELLI, G.; GIACHETI, H.L.; HAMADA, J.; ELIS, V.R. (2O10) Determinação de pluma(s) de contaminação de um aterro de resíduos sólidos urbanos utilizando poços de monitoramento e eletrorresistividade. In: Congresso Brasileiro de Mecânica dos Solos e Engenharia Geotécnica, 15 2010, Gramado-RS. CD-ROM.

QASIM, S.R. \& CHIANG, W. (1994) Sanitary landfill leachate - Generation, control and treatment. Lancaster, PA: Technomic publishing Co., Inc. 323 p.

SÁNCHEZ, L.E. (2001) Desengenharia: O passivo ambiental na desativação de empreendimentos industriais. São Paulo: Editora da Universidade de São Paulo. 254 p. 